\title{
Sclerosing adenosis and risk of breast cancer
}

\author{
Daniel W. Visscher - Aziza Nassar - Amy C. Degnim - Marlene H. Frost • \\ Robert A. Vierkant · Ryan D. Frank - Yaman Tarabishy • Derek C. Radisky • \\ Lynn C. Hartmann
}

Received: 24 January 2014/ Accepted: 24 January 2014/Published online: 8 February 2014

(C) The Author(s) 2014. This article is published with open access at Springerlink.com

\begin{abstract}
Over one million American women have a benign breast biopsy annually. Sclerosing adenosis (SA) is a common, but poorly understood benign breast lesion demonstrating increased numbers of distorted lobules accompanied by stromal fibrosis. Few studies of its association with breast cancer have been conducted, with contradictory results. We studied SA in the Mayo Benign Breast Disease (BBD) Cohort, which includes women who had benign biopsies at Mayo-Rochester 1967-2001. Breast
\end{abstract}

D. W. Visscher

Department of Laboratory Medicine and Pathology, Mayo Clinic, Rochester, MN, USA

A. Nassar

Department of Laboratory Medicine and Pathology, Mayo

Clinic, Jacksonville, FL, USA

A. C. Degnim

Department of Surgery, Mayo Clinic, Rochester, MN, USA

M. H. Frost · L. C. Hartmann ( $\square)$

Department of Oncology, Mayo Clinic, Rochester, MN, USA

e-mail: hartmann.lynn@mayo.edu

R. A. Vierkant

Department of Health Sciences Research, Mayo Clinic,

Rochester, MN, USA

R. D. Frank

Department of Biomedical Statistics and Informatics, Mayo

Clinic, Rochester, MN, USA

Y. Tarabishy

Department of Pathology, Washington University, St. Louis, MO, USA

D. C. Radisky

Department of Biochemistry/Molecular Biology, Mayo Clinic, Jacksonville, FL, USA cancer risk in defined subsets was assessed using standardized incidence ratios (SIRs), relative to the Iowa Surveillance, Epidemiology, and End Results registry. This BBD cohort of 13,434 women was followed for a median of 15.7 years. SA was present in 3,733 women $(27.8 \%)$ who demonstrated an SIR for breast cancer of $2.10(95 \%$ CI 1.91-2.30) versus an SIR of 1.52 (95 \% CI 1.42-1.63) for the 9,701 women without SA. SA was present in $62.4 \%$ of biopsies with proliferative disease without atypia and $55.1 \%$ of biopsies with atypical hyperplasia. The presence of SA stratified risk in subsets of women defined by age, involution status, and family history. However, SA does not further stratify risk in women diagnosed with other forms of proliferative breast disease, either with or without atypia. SA is a common proliferative lesion of the breast which, as a single feature, conveys an approximate doubling of breast cancer risk. Its role in breast carcinogenesis remains undefined; its presence may aid in risk prediction for women after a breast biopsy.

Keywords Benign breast disease - Breast carcinoma . Sclerosing adenosis

\section{Introduction}

Sclerosing adenosis (SA) is a proliferative lesion that is commonly found in benign breast biopsies [1]. It is a histologically complex entity that consists of enlarged and distorted lobules, containing duplicated and crowded acini, with prominent myoepithelium and stromal fibrosis (Fig. 1). The literature addressing the risk of breast cancer following a diagnosis of SA is limited. Jensen and Page studied 349 women with SA diagnosed between 1950 and 1968 and found a relative risk for breast cancer of 2.1 [2]. 

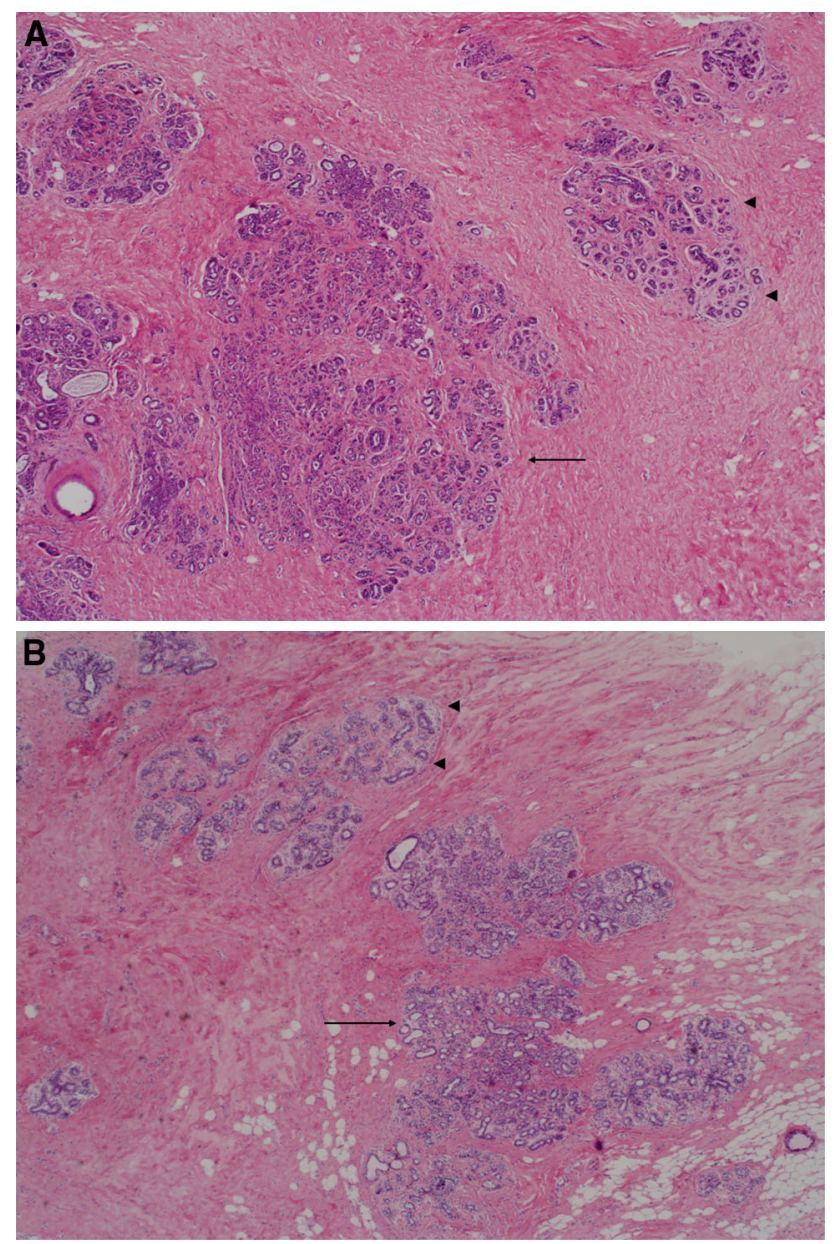

Fig. $1 \times 20$ photomicrographs of sclerosing adenosis. a Large, central area of SA (arrow), with diameter larger than the normal lobular units pictured to the right (arrow heads). This SA would be classified as PDWA. b A lobular unit with sclerosing adenosis but without significant increase in its diameter (arrow): compare with normal lobular unit (arrow heads). This would be classified as NP

Other studies, however, have found no increased risk in women with SA [3, 4]. To our knowledge, the underlying biology of SA is undefined. Utilizing the Mayo Benign Breast Disease Cohort, we studied the prevalence of SA and its relationship to defined risk factors for breast cancer. We also examined the risk of breast cancer in women diagnosed with SA who have been followed long term. A clear understanding of the risk associated with SA is needed to underlie recommendations for clinical management.

\section{Materials and methods}

Study population

The Mayo Benign Breast Disease Cohort originally included 9,038 women aged 18-85 years who had a benign breast biopsy at Mayo Clinic Rochester from January 1,
1967 to December 31, 1991 [5, 6]. Using the same inclusion/exclusion criteria [5], we have extended the cohort through 12/31/2001, which now includes 13,434 women. Follow-up for breast cancer events, including both invasive cancer and ductal carcinoma in situ, and risk factor information, were obtained using the Mayo Clinic medical record, Mayo Tumor Registry and a study-specific questionnaire mailed to study participants or next of kin [5, 6]. Family history was classified as negative, weak, or strong. A strong family history included at least one first-degree relative with breast cancer before age 50, or two or more relatives with breast cancer, with at least one being a firstdegree relative. Any lesser degree of family history was defined as weak [5].

\section{Histologic examination}

Archival hematoxylin and eosin-stained sections from each participant were evaluated by a breast pathologist (DWV), who was unaware of the initial histological diagnoses and patient outcomes. For women who had more than one biopsy during this period, we used the earliest biopsy performed. Benign breast lesions were systematically classified according to the criteria of Dupont and Page [7] into one of the following general categories: non-proliferative changes (NP), proliferative disease without atypia (PDWA), and proliferative disease with atypia (atypical ductal hyperplasia $[\mathrm{ADH}]$, atypical lobular hyperplasia [ALH], or both) [5]. SA was defined as cellular lobulocentric proliferation of both epithelium and myoepithelium, consisting of compressed and crowded gland-like acini, usually associated with fibrosis (Figs. 1,2). SA was included in the PDWA category if it was present in at least two lobular units, and at least one had a diameter greater than one (preinvoluted) normal-sized lobule (Fig. 1a); any lesser degree of SA was classified as NP, assuming no other proliferative lesions were present (Fig. 1b). Biopsies with SA were further characterized by whether individual SA foci were homogeneous or combined with columnar cell alterations (Fig. 2) [8]. For a subset of the women with SA (those biopsied 1967-1991, $n=2,639$ ), the number of foci of SA was recorded (1-3 vs $>3$ ). The extent of lobular involution was assessed in the normal background breast lobules on a hematoxylin \& eosin-stained slide. The degree of involution was classified into three categories: no involution ( $0 \%$ involuted lobules), partial (1-74 \% involuted lobules), or complete (at least $75 \%$ involuted lobules) [6].

\section{Statistical analysis}

Data were descriptively summarized using frequencies and percents for categorical variables and means and standard 

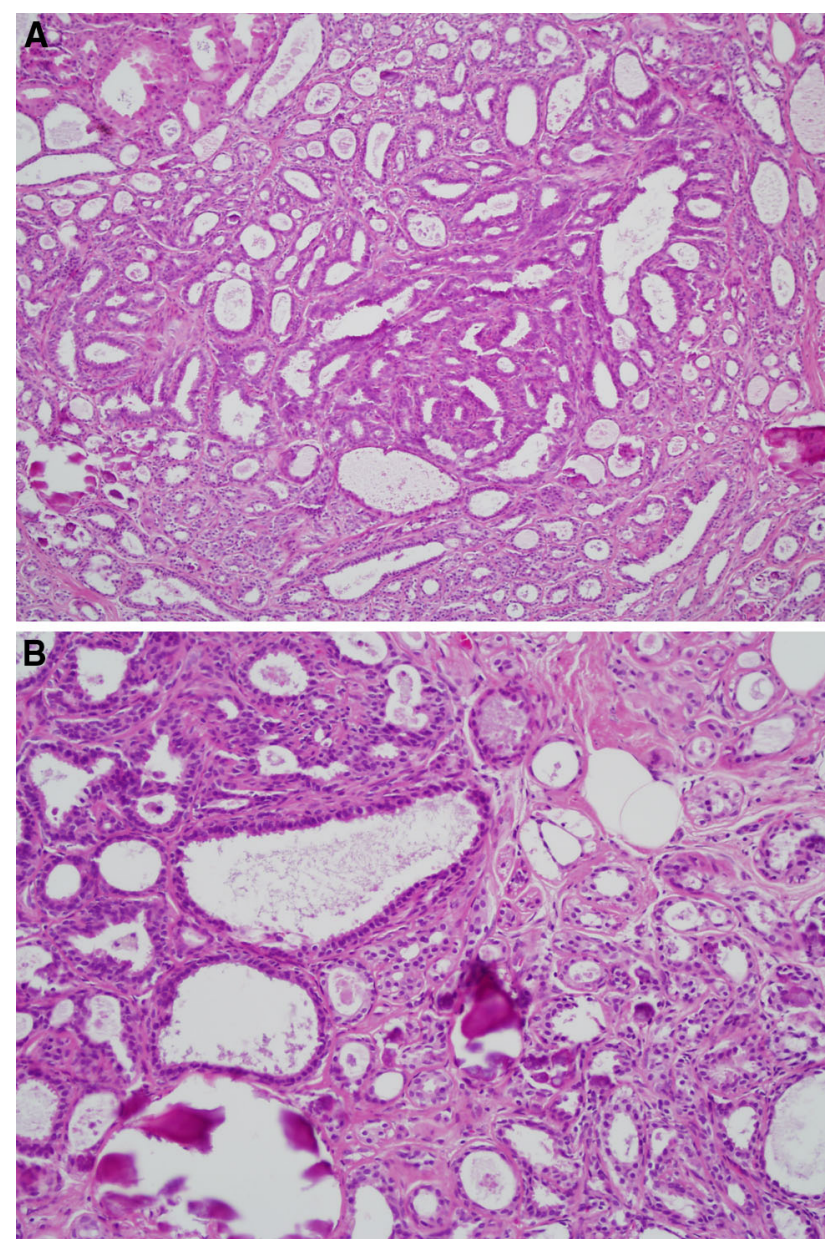

Fig. 2 Mixed adenosis/columnar lesion. a Low-magnification $(\times 100)$ view shows a markedly enlarged terminal duct lobular unit comprised of admixed microacini (adenosis)with larger cystic acini lined by columnar cells. b Higher-magnification $(\times 200)$ photomicrograph of the same lobule highlighting columnar acini (left) and smaller microacini characteristic of adenosis (right). Microcalcifications are present

deviations for continuous variables. We compared presence of SA across levels of categorical variables (including age at biopsy, year of biopsy, histological impression, extent of involution, columnar cell alteration, family history of breast cancer, postmenopausal hormonal therapy use [HRT], and parity) using $\chi^{2}$ tests of significance. All variables found in a univariate analysis to be associated with SA $(p<0.05)$ were then included in a multivariate logistic regression analysis to assess associations independent of other effects.

The duration of follow-up was calculated as the number of days from biopsy of the benign lesion to the date of the diagnosis of breast cancer, death, prophylactic mastectomy, reduction mammoplasty, LCIS, or last contact. We estimated relative risks (RR) using standardized incidence ratios (SIRs) and corresponding $95 \%$ confidence intervals (CIs), dividing the observed numbers of incident breast cancers by population-based expected counts. We calculated these expected counts by apportioning each woman's follow-up into 5-year age and calendar period categories, thereby accounting for differences associated with these variables. We used the Iowa Surveillance, Epidemiology, and End Results (SEER) registry [9] as the reference population because of its demographic similarities to the Mayo Clinic population ( $80 \%$ of cohort members reside in the upper Midwest). Over $95 \%$ of our cohort was Caucasian, equivalent to that reported in Iowa census data during the study period [5]. SIRs were calculated both overall and by subgroups defined by SA and other demographic and clinical characteristics. We assessed potential heterogeneity in SIRs across subgroups using Poisson regression analysis, with the $\log$ transformed expected event rate for each individual modeled as the offset term.

\section{Results}

Clinical and histologic characteristics

There are 13,434 women in the Mayo Benign Breast Disease Cohort, with median follow-up of 15.7 years. Overall, SA was present in biopsies from 3,733 women (27.8\%); most of these $[(2,672 / 4,285(62.4 \%)]$ were classified as PDWA. SA was present only focally in another 675 biopsies characterized as non-proliferative $(18.1 \%$ of all SA biopsies; $8.0 \%$ of all NP biopsies). Of the 700 women with atypical hyperplasia, $386(55.1 \%)$ also had SA. Table 1 summarizes the association of SA with various clinical and histological parameters.

SA was most common in women aged 45-55 years $(34.0 \%$ ), versus $28.3 \%$ of women greater than 55 years or $21.6 \%$ of women less than 45 years $(p<0.0001$, Table 1$)$. Biopsies performed in the post-mammography era (1982-2001) were somewhat more likely to contain SA than those biopsied before 1981 (28.9 vs $25.4 \%$, $p<0.0001)$. SA was commonly seen in association with columnar cell alterations, another lesion in the category of PDWA, and these often occurred together in the same terminal duct lobular unit (TDLU). Specifically, of the 3733 women with SA in the cohort, 3,161 (84.7\%) also had columnar cell alterations. SA occurred commonly in biopsies with atypical hyperplasia, with similar frequency for ADH and ALH, (52.6 and 56.5\%, respectively, $p=0.31$; Table 2). Examining the presence of SA by extent of lobular involution, SA was significantly less frequent in women with complete lobular involution $(p<0.0001)$.

SA was more common in women with a strong family history of breast cancer [32.4 vs $26.9 \%$ of women with no family history $(p<0.0001)]$, in women who used HRT 
Table 1 Clinical and histologic characteristics by presence/ absence of sclerosing adenosis
Numbers may not add to total number of subjects due to missing values for some variables

${ }^{\mathrm{a}} p$ value from $\chi^{2}$ test

${ }^{\mathrm{b}} p$ value from multivariate logistic regression adjusting for age, year of BBD, histology, involution, columnar call alteration, family history, HRT use, and number of children. Only variables univariately significant were included in the multivariate analysis

${ }^{c}$ No normal terminal duct lobular units present on the slide, so involution could not be assessed

\begin{tabular}{|c|c|c|c|c|c|}
\hline & $\begin{array}{l}\text { Overall } \\
(N=13,434)\end{array}$ & $\begin{array}{l}\text { No } \\
(N=9,701)\end{array}$ & $\begin{array}{l}\text { Yes } \\
(N=3,733)\end{array}$ & $p$ value $^{\mathrm{a}}$ & $p$ value $^{\mathrm{b}}$ \\
\hline Histology & & & & $<0.0001$ & $<0.0001$ \\
\hline NP & 8,449 & 7,774 (92.0\%) & $675(8.0 \%)$ & & \\
\hline PDWA & 4,285 & $1,613(37.6 \%)$ & $2,672(62.4 \%)$ & & \\
\hline $\mathrm{AH}$ & 700 & $314(44.9 \%)$ & $386(55.1 \%)$ & & \\
\hline Age at BBD diagnosis & & & & $<0.0001$ & 0.7377 \\
\hline$<45$ & 4,375 & $3,432(78.4 \%)$ & $943(21.6 \%)$ & & \\
\hline $45-55$ & 3,943 & $2,602(66.0 \%)$ & $1,341(34.0 \%)$ & & \\
\hline $55+$ & 5,116 & $3,667(71.7 \%)$ & $1,449(28.3 \%)$ & & \\
\hline Year of BBD & & & & $<0.0001$ & $<0.0001$ \\
\hline 1967-1981 & 4,299 & $3,205(74.6 \%)$ & $1,094(25.4 \%)$ & & \\
\hline $1982-2001$ & 9,135 & $6,496(71.1 \%)$ & $2,639(28.9 \%)$ & & \\
\hline Involution & & & & $<0.0001$ & $<0.0001$ \\
\hline Unknown $^{c}$ & 1,249 & 1,115 & 134 & & \\
\hline No & 2,250 & $1,642(73.0 \%)$ & $608(27.0 \%)$ & & \\
\hline $1-74 \%$ TDLU & 6,633 & $4,116(62.1 \%)$ & $2,517(37.9 \%)$ & & \\
\hline$>75 \%$ TDLU & 3,302 & $2,828(85.6 \%)$ & $474(14.4 \%)$ & & \\
\hline Columnar cell alteration & & & & $<0.0001$ & $<0.0001$ \\
\hline No & 8,963 & $8,391(93.6 \%)$ & $572(6.4 \%)$ & & \\
\hline Yes & 4,467 & $1,306(29.2 \%)$ & $3,161(70.8 \%)$ & & \\
\hline Family history of breast cancer & & & & $<0.0001$ & 0.0365 \\
\hline Unknown & 858 & 684 & 174 & & \\
\hline None & 7,506 & $5,485(73.1 \%)$ & $2,021(26.9 \%)$ & & \\
\hline Weak & 3,339 & $2,362(70.7 \%)$ & $977(29.3 \%)$ & & \\
\hline Strong & 1,731 & $1,170(67.6 \%)$ & $561(32.4 \%)$ & & \\
\hline HRT use & & & & $<0.0001$ & 0.8649 \\
\hline Unknown & 3,993 & 3,046 & 947 & & \\
\hline Never used HRT & 4,199 & $3,134(74.6 \%)$ & $1,065(25.4 \%)$ & & \\
\hline Used HRT & 5,242 & $3,521(67.2 \%)$ & $1,721(32.8 \%)$ & & \\
\hline Number of children & & & & $<0.0001$ & 0.3792 \\
\hline Unknown & 3,422 & 2,626 & 796 & & \\
\hline Nulliparous & 1,399 & $1,042(74.5 \%)$ & $357(25.5 \%)$ & & \\
\hline 1 & 1,064 & $781(73.4 \%)$ & $283(26.6 \%)$ & & \\
\hline 2 & 2,985 & $2,146(71.9 \%)$ & $839(28.1 \%)$ & & \\
\hline $3+$ & 4,564 & $3,106(68.1 \%)$ & $1,458(31.9 \%)$ & & \\
\hline
\end{tabular}

$(p<0.0001)$, and in parous women $(p<0.0001)$. The presence of SA was not associated with body mass index (data not shown). In multivariate analysis, associations between presence of SA and age, HRT use and parity attenuated to the point of non-significance, whereas SA remained significantly associated with major histologic category of $\mathrm{BBD}$, year of benign biopsy, degree of involution, columnar cell alterations, and family history.

Association of histologic and clinical features with subsequent breast cancer risk

As a whole, the cohort of 13,434 women with BBD was at increased risk of breast cancer (SIR 1.69 [95\% CI
1.60-1.79]) compared to the reference general population. Across the entire cohort, women with SA had a higher risk of developing breast cancer (SIR 2.10, $95 \%$ CI 1.91-2.30) than those without SA (SIR 1.52, $95 \%$ CI 1.42-1.63, test for heterogeneity $p<0.0001$, Table 2 ). However, when running subset analyses within the major histologic categories of non-proliferative disease, PDWA, or atypical hyperplasia, the presence of SA did not provide further risk stratification (Fig. 3). Specifically, the SIRs for these three histologic categories, with or without SA were: NP, 1.39 versus $1.34, p=0.78$; PDWA, 1.97 versus $1.99, p=0.95$; and $\mathrm{AH}, 4.76$ versus $4.16, p=0.42$ (95\% CIs in Table 2). Of note, SA did stratify risk for subsets of women defined by other features, including age at BBD, extent of normal 
Table 2 Association of sclerosing adenosis and other risk factors with risk of breast cancer

\begin{tabular}{|c|c|c|c|c|c|c|c|c|c|}
\hline \multirow[t]{2}{*}{ Characteristic } & \multicolumn{4}{|c|}{ SA absent } & \multicolumn{4}{|c|}{ SA present } & \multirow[t]{2}{*}{$p$ value } \\
\hline & $\begin{array}{l}\text { No. } \\
\text { women }\end{array}$ & $\begin{array}{l}\text { Observed } \\
\text { events }\end{array}$ & $\begin{array}{l}\text { Expected } \\
\text { events }\end{array}$ & $\begin{array}{l}\text { SIR } \\
(95 \% \mathrm{CI})\end{array}$ & $\begin{array}{l}\text { No. } \\
\text { women }\end{array}$ & $\begin{array}{l}\text { Observed } \\
\text { events }\end{array}$ & $\begin{array}{l}\text { Expected } \\
\text { events }\end{array}$ & $\begin{array}{l}\text { SIR } \\
(95 \% \text { CI })\end{array}$ & \\
\hline Overall & 9,701 & 778 & 511 & $1.52(1.42,1.63)$ & 3,733 & 458 & 218 & $2.10(1.91,2.30)$ & $<0.0001$ \\
\hline \multicolumn{10}{|l|}{ Histology } \\
\hline NP & 7,774 & 552 & 413 & $1.34(1.23,1.45)$ & 675 & 59 & 42 & $1.39(1.06,1.79)$ & 0.7840 \\
\hline PDWA & 1,613 & 166 & 84 & $1.99(1.70,2.31)$ & 2,672 & 311 & 158 & $1.97(1.76,2.21)$ & 0.9514 \\
\hline $\mathrm{AH}$ & 314 & 60 & 14 & $4.16(3.18,5.36)$ & 386 & 88 & 18 & $4.76(3.82,5.86)$ & 0.4206 \\
\hline \multicolumn{10}{|l|}{ Type of atypia } \\
\hline $\mathrm{ADH}$ & 148 & 26 & 7 & $3.85(2.51,5.64)$ & 164 & 37 & 8 & $4.80(3.38,6.61)$ & 0.3867 \\
\hline ALH & 146 & 27 & 7 & $3.91(2.57,5.69)$ & 190 & 45 & 9 & $4.87(3.55,6.52)$ & 0.3606 \\
\hline $\mathrm{ADH}$ and ALH & 17 & 6 & 1 & $8.59(3.15,18.69)$ & 27 & 6 & 1 & $4.72(1.73,10.26)$ & 0.3024 \\
\hline \multicolumn{10}{|l|}{ Age } \\
\hline$<45$ & 3,432 & 222 & 129 & $1.72(1.50,1.96)$ & 943 & 91 & 43 & $2.12(1.71,2.60)$ & 0.1004 \\
\hline $45-55$ & 2,602 & 257 & 166 & $1.55(1.37,1.75)$ & 1,341 & 194 & 87 & $2.24(1.94,2.58)$ & 0.0001 \\
\hline$>55$ & 3,667 & 299 & 216 & $1.38(1.23,1.55)$ & 1,449 & 173 & 89 & $1.94(1.66,2.25)$ & 0.0005 \\
\hline \multicolumn{10}{|l|}{ Involution } \\
\hline None & 1,642 & 142 & 77 & $1.85(1.56,2.18)$ & 608 & 89 & 33 & $2.67(2.14,3.28)$ & 0.0076 \\
\hline Partial & 4,116 & 360 & 233 & $1.55(1.39,1.72)$ & 2,517 & 313 & 153 & $2.04(1.82,2.28)$ & 0.0004 \\
\hline Complete & 2,828 & 164 & 156 & $1.05(0.90,1.23)$ & 474 & 37 & 26 & $1.43(1.01,1.97)$ & 0.1049 \\
\hline \multicolumn{10}{|c|}{ Columnar alteration } \\
\hline Absent & 8,391 & 643 & 448 & $1.43(1.33,1.55)$ & 572 & 60 & 32 & $1.88(1.43,2.41)$ & 0.0559 \\
\hline Present & 1,306 & 134 & 62 & $2.15(1.80,2.55)$ & 3,161 & 398 & 187 & $2.13(1.93,2.35)$ & 0.9393 \\
\hline \multicolumn{10}{|l|}{ Family history } \\
\hline None & 5,485 & 367 & 293 & $1.25(1.13,1.39)$ & 2,021 & 210 & 119 & $1.77(1.54,2.02)$ & $<0.0001$ \\
\hline Weak & 2,362 & 241 & 130 & $1.85(1.62,2.10)$ & 977 & 144 & 59 & $2.46(2.07,2.90)$ & 0.0078 \\
\hline Strong & 1,170 & 149 & 68 & $2.18(1.84,2.55)$ & 561 & 100 & 35 & $2.85(2.31,3.46)$ & 0.0399 \\
\hline
\end{tabular}

SIRs compare the observed number of breast cancer events with the number expected on the basis of Iowa SEER Data. All analyses account for the effects of age and calendar period

lobular involution, and family history (Table 2; Fig. 3), suggesting that the risk associated with SA is independent of these other factors. For example, women aged 45-55 years at initial biopsy with SA had SIR $2.24(95 \%$ CI 1.94-2.58), versus SIR 1.55 (95 \% CI 1.37-1.75, $p=0.0001$ ) for those without SA. For women over 55, the corresponding SIRs are 1.94 (95\% CI 1.66-2.25) with SA versus 1.38 (95 \% CI 1.23-1.55) without. Crossing involution status by the presence or absence of SA yielded distinct risk groups: women with no involution and SA had SIR 2.67 (2.14-3.28) versus those with complete involution and no SA [SIR 1.05 (0.90-1.23)]. Examining SA by family history categories, there was similar stratification: women with no family history and no SA had SIR 1.25 (95\% CI 1.13-1.39) versus 2.85 (2.31-3.46) for those with a family history and SA. When columnar alteration was present, SA did not provide further risk stratification; however, when columnar alteration was absent, the presence of SA appeared to increase risk [1.88 with SA vs 1.43 without $(p=0.056)]$.
Further, we examined whether the presence of an admixture of SA and columnar cell alterations on the same slide, as opposed to their being present on different slides, might be associated with a differing level of risk, but no difference was seen (data not shown). Regarding the risks by number of foci of SA, 1,817 women had 1-3 foci of SA with SIR 1.89 (95\% CI 1.66-2.16) and 822 women had $>3$ foci with SIR 2.27 (95\% CI 1.88-2.72), $p=0.12$.

\section{Discussion}

In this study based in the Mayo Benign Breast Disease Cohort, we demonstrate that SA is common, occurring in $27.8 \%$ of all benign biopsies, and in nearly two-thirds (62.4\%) of women with PDWA. When considering any type of benign breast biopsy, SA is associated with an increased risk of breast cancer (SIR 2.10 vs 1.52 when SA absent). However, if women have other types of proliferative disease or atypical hyperplasia, then the co-existence of SA does not 
Risk by presence/absence of SA and age
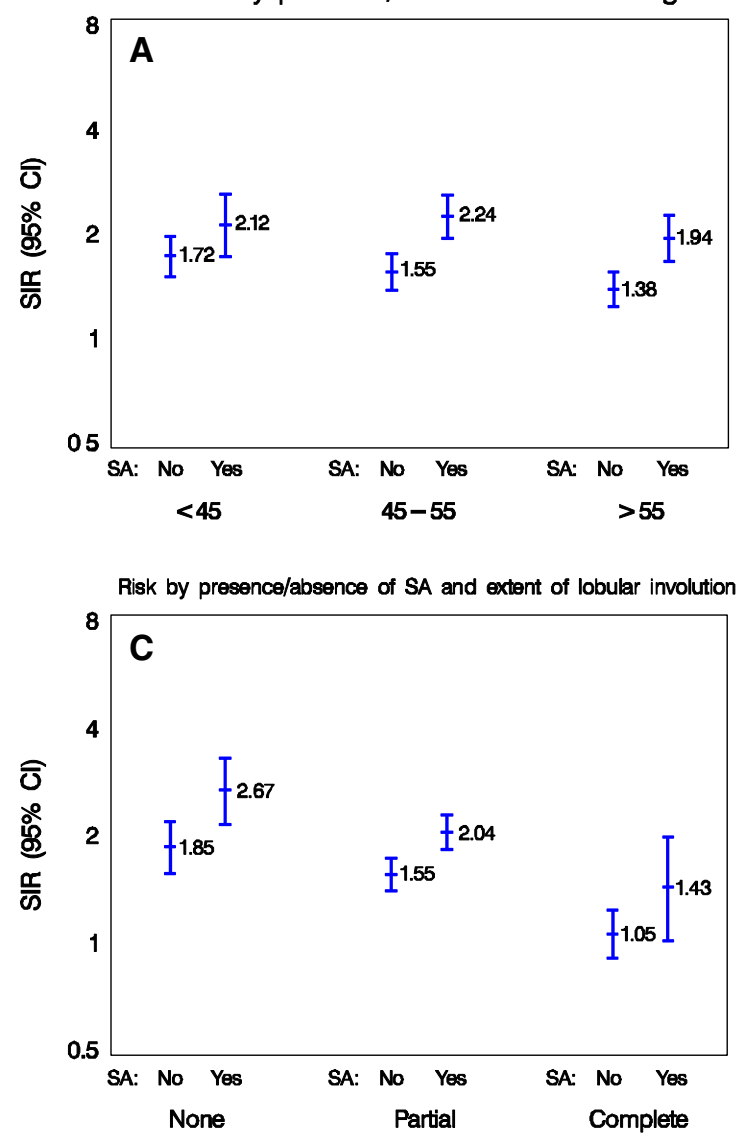

Risk by presence/absence of SA and histology
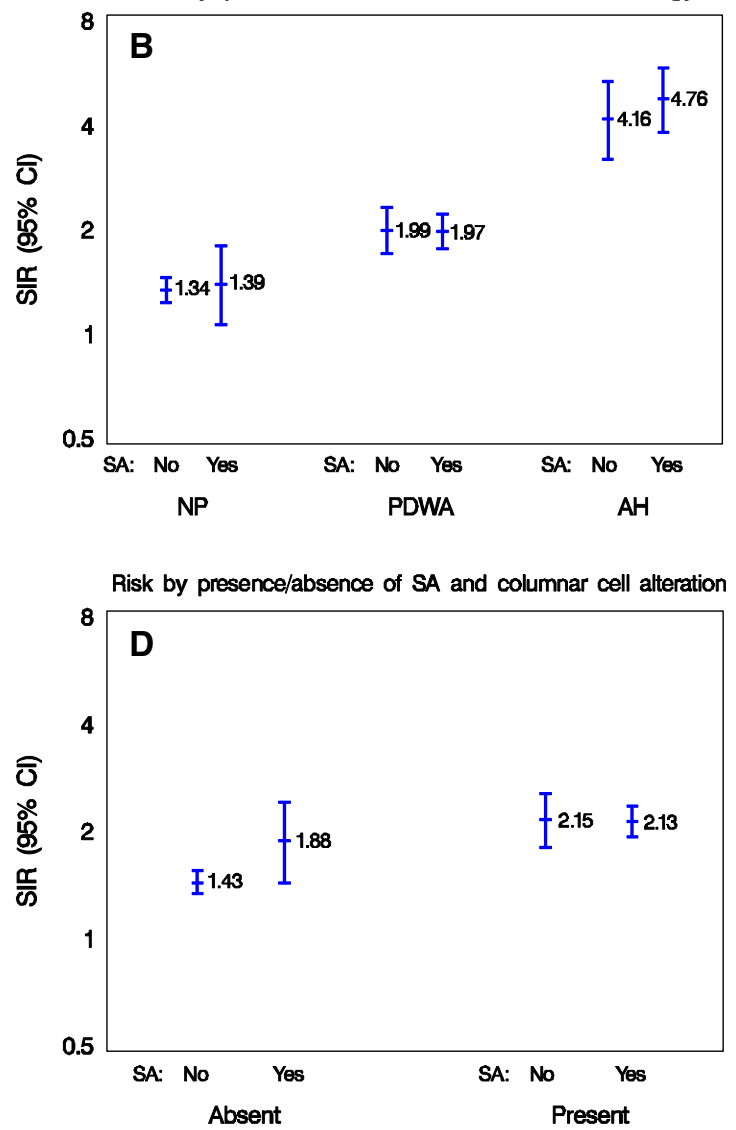

Risk by presence/absence of SA and family history

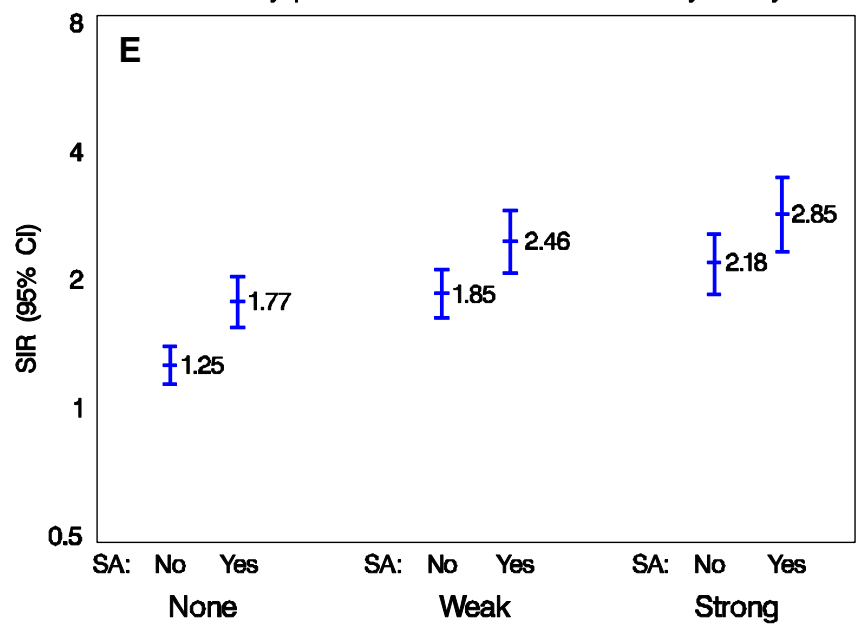

Fig. 3 Risk factor interaction profiles for sclerosing adenosis, comparing the number of events observed with the number expected. a Age and sclerosing adenosis, b Histology and SA, $\mathbf{c}$ Extent of lobular involution and SA, d Columnar cell alterations and SA, and e Family history and SA

provide further risk stratification. When examining subsets of women differing by age, involution status, and extent of family history, however, the presence of SA does convey independent risk information (Fig. 3; Table 2). Thus, given the commonality of SA, its recognition on benign biopsies may serve to enhance risk prediction.
The identification of increased cancer risk for patients with SA suggests that tumorigenic alterations may be associated with the pathogenesis of this lesion. Histologically, SA is a complex proliferative alteration, comprised of enlarged lobules, containing duplicated, crowded acini [2]. Although the cellular composition can be difficult to 
appreciate due to architectural distortion, the acini in SA include abundant myoepithelial, in addition to luminal epithelial cells (Fig. 2). The process is usually accompanied by stromal fibrosis. As such, SA combines proliferation of epithelial, myoepithelial, and mesenchymal cells, which differs from the more homogeneous proliferation of luminal epithelial cells seen in usual ductal hyperplasias [1]. This concurrent aberration of epithelial and mesenchymal compartments in SA appears to set the stage for a higher likelihood of subsequent malignancy. There are likely phenotypic changes in these cells resulting from microenvironmental signals that stimulate progression to more advanced stages of BBD or carcinoma [10]. It has been shown that myoepithelial cells in DCIS show decreased expression of genes involved in normal cell function and increased expression of genes that stimulate proliferation, migration, invasion, and angiogenesis [1113]; similarly, DCIS-associated mesenchymal cells can drive progression to invasive disease through deposition and modification of extracellular matrix molecules and through recruitment of other stromal components [14, 15]. In benign tissue, we have found that some molecular mediators associated with poor prognosis for patients with DCIS are also associated with future cancer risk, including COX2 and Ki67 in atypia [16, 17]. Our finding of increased breast cancer risk associated with SA suggests that key pretumorigenic alterations are already occurring in some of these patients. Identification of those alterations associated with progression to cancer could advance risk prediction for women with SA, and provide insight into driving early events in breast carcinogenesis.

The prior literature examining SA as a risk factor for breast cancer is limited and contradictory. Jensen and Page identified 349 women with SA diagnosed on breast biopsies in Nashville, TN, obtained between 1950 and 1968 [2] and reported that these women were at increased risk of breast cancer (relative risk for invasive breast cancer 2.1) compared to similar-aged women in the general population. In the subset of 21 women with both $\mathrm{SA}$ and $\mathrm{AH}$, the relative risk was 6.7 (95\% CI 2.53-17.95). When they excluded women with co-existent atypical hyperplasia, the relative risk for the SA group decreased to 1.7. Shaaban et al. [3], using a case-control design, followed 67 women with SA and found no evidence of an increased risk of later breast cancer. Kabat et al. also used a nested case-control study to evaluate the breast cancer risk of several benign lesions including SA. In 298 women with SA, they saw no increased risk of subsequent breast cancer [4]. Ashbeck et al. [18] examined benign breast biopsy diagnoses in the New Mexico Mammography Project and observed a hazard ratio for breast cancer of 2.28 (95\% CI 1.64-3.17) in patients with SA. In that study, however, histologic diagnoses were abstracted from the text of archival pathology reports and not confirmed by central pathology review.

With this cohort of 3,733 women with SA, we were able to study clinical and histologic features associated with its occurrence. We show that SA is common, found in just over one-fourth of benign breast biopsies. SA is more frequent in women with a family history of breast cancer and in those where lobular involution has not been initiated or is still ongoing. Most SA occurs with columnar cell alterations, another component of proliferative breast disease. Notably, SA is also seen commonly with atypical hyperplasia.

The extent of SA can vary considerably, from a microscopic focus smaller than a normal lobule to a confluent process that may resemble malignancy by virtue of marked cellularity. While generally the amount of SA present is sufficient to classify the lesion as proliferative, we also made note of only focal evidence of SA, placing such small lesions in the non-proliferative category. Importantly, when only such a small area of adenosis was present, we saw no evidence that risk was elevated beyond that of other non-proliferative findings (Table 2). This is comparable to findings with usual ductal hyperplasia, where only a mild degree of hyperplasia is categorized as non-proliferative. Our comparison of number of foci of SA (1-3 vs $>3$ ) did not show a significant difference in risk, but our approach may not adequately address the risk of greater versus lesser volume of SA, where a single focus can extend over a sizable area.

In summary, SA is a unique histologic finding that reflects an abnormal breast tissue bed, with disturbances of both the epithelial and mesenchymal compartments. In this large cohort study, we show that adenosis is found in $28 \%$ of all benign biopsies and, as a single feature, is associated with a doubling of risk of breast cancer. The presence (or absence) of SA can help stratify risk of breast cancer in groups of women defined by clinical features such as age or family history. Further study of SA is merited as a recognizable tissue anomaly associated with the later development of breast cancer. In addition, making note of its presence or absence may aid risk prediction efforts for women with benign breast biopsies.

Acknowledgments We are grateful to Teresa Allers, Mary Campion, Joanne Johnson, and Melanie Kasner for data collection; to Ann Harris and the Survey Research Center for patient follow-up; Vicki Shea for help in preparing the manuscript; and Pat Haugen, patient advocate, for her guidance and support. This study was supported by the National Cancer Institute (NCI RO1 CA 132879; to LCH); Mayo Clinic Breast Cancer-Specialized Program of Research Excellence (SPORE CA 116201; to DWV, DCR, and LCH); Martha and Bruce Atwater (to DWV, DCR, and LCH); Jimmy V Foundation (to DCR and $\mathrm{LCH}$ ); and the Susan B Komen Foundation (to DCR and LCH). 
Conflict of interest The authors have no known conflicts of interest.

Open Access This article is distributed under the terms of the Creative Commons Attribution Noncommercial License which permits any noncommercial use, distribution, and reproduction in any medium, provided the original author(s) and the source are credited.

\section{References}

1. Santen RJ, Mansel R (2005) Benign breast disorders. N Engl J Med 353(3):275-285

2. Jensen RA, Page DL, Dupont WD et al (1989) Invasive breast cancer risk in women with sclerosing adenosis. Cancer 64:1977-1983

3. Shaaban AM, Sloane JP, West CR, Moore FR, Jarvis C, Williams EM, Foster CS (2002) Histopathologic types of benign breast lesions and the risk of breast cancer: case-control study. Am J Surg Pathol 26(4):421-430

4. Kabat GC, Jones JG, Olson NK, Negassa A, Duggan C, Ginsberg M, Kandel RA, Glass AG, Rohan TE (2010) A multi-center prospective cohort study of benign breast disease and risk of subsequent breast cancer. Cancer Causes Control 21(6):821-828

5. Hartmann LC, Sellers TA, Frost MH, Lingle WL, Degnim AC, Ghosh K, Vierkant RA, Maloney SD, Pankratz VS, Hillman DW et al (2005) Benign breast disease and the risk of breast cancer. N Engl J Med 353(3):229-237

6. Milanese TR, Hartmann LC, Sellers TA, Frost MH, Vierkant RA, Maloney SD, Pankratz VS, Degnim AC, Vachon CM, Reynolds $\mathrm{CA}$ et al (2006) Age-related lobular involution and risk of breast cancer. J Natl Cancer Inst 98(922):1600-1607

7. Dupont WD, Page DL (1985) Risk factors for breast cancer in women with proliferative breast disease. $\mathrm{N}$ Eng $\mathrm{J}$ Med 312:146-151

8. Schnitt SJ, Vincent-Salomon A (2003) Columnar cell lesions of the breast. Adv Anat Pathol 10:113-124.007; 60:1307-1312
9. Surveillance, Epidemiology, and End results (1999) http://www. seer.cancer.gov. Accessed 9 July 2009

10. Cichon MA, Degnim AC, Visscher DW, Radisky DC (2010) Microenvironmental influences that drive progression from benign breast disease to invasive breast cancer. J Mammary Gland Biol Neoplasia 15(4):389-397

11. Polyak K, Hu M (2005) Do myoepithelial cells hold the key for breast tumor progression? J Mammary Gland Biol Neoplasia 10(3):231-247

12. Allinen M, Beroukhim R, Cai L, Brennan C, Lahti-Domenici J, Huang H, Porter D, Hu M, Chin L, Richardson A, Schnitt S, Sellers WR, Polyak K (2004) Molecular characterization of the tumor microenvironment in breast cancer. Cancer Cell 6(1): $17-32$

13. Hilson JB, Schnitt SJ, Collins LC (2009) Phenotypic alterations in ductal carcinoma in situ-associated myoepithelial cells: biologic and diagnostic implications. Am J Surg Pathol 33(2):227-232

14. Kalluri R, Zeisberg M (2006) Fibroblasts in cancer. Nat Rev Cancer 6(5):392-401

15. Hu M, Peluffo G, Chen H, Gelman R, Schnitt S, Polyak K (2009) Role of COX-2 in epithelial-stromal cell interactions and progression of ductal carcinoma in situ of the breast. Proc Natl Acad Sci USA 106(9):3372-3377

16. Visscher DW, Pankratz VS, Santisteban M, Reynolds C, Ristimäki A, Vierkant RA, Lingle WL, Frost MH, Hartmann LC (2008) Association between cyclooxygenase-2 expression in atypical hyperplasia and risk of breast cancer. J Natl Cancer Inst 100(6):421-427

17. Santisteban M, Reynolds C, Barr Fritcher EG, Frost MH, Vierkant RA, Anderson SS, Degnim AC, Visscher DW, Pankratz VS, Hartmann LC (2010) Ki67: a time-varying biomarker of risk of breast cancer in atypical hyperplasia. Breast Cancer Res Treat 121(2):431-437

18. Ashbeck EL, Rosenberg RD, Stauber PM, Key CR (2007) Benign breast biopsy diagnosis and subsequent risk of breast cancer. Cancer Epidemiol Biomarkers Prev 16(3):467-472 